\title{
Xiaochaihu Decoction attenuates the vicious circle between the oxidative stress and the ALP inactivation through LPS-catecholamines interactions in gut, liver and brain during $\mathrm{CCl}_{4}$ +ethanol-induced mouse $\mathrm{HCC}$
}

\author{
Xiao-qiu Liu ${ }^{1 *}$, Xiao-jian $\mathrm{Hu}^{2}$, Hong-Xing $\mathrm{Xu}^{1}$ and Xiao-Ying Zeng ${ }^{1}$
}

\begin{abstract}
Background: Xiaochaihu Decoction (XCHD) prevents hepatocarcinogenesis in association with inhibition of oxidative stress. However, alkaline phosphatase (ALP) activity, lipopolysaccharides (LPS)-catecholamines (CA) interactions in gut, liver and brain may play an important role in the status of oxidative stress. This study was to assess whether XCHD attenuates the vicious circle between oxidative stress and ALP inactivation through LPS-CA interactions
\end{abstract}

Methods: Hepatocellular carcinoma group (HCC) were induced by $\mathrm{CCl}_{4}+$ ethanol; $\mathrm{HCC}$ with Liver Depression and Spleen Deficiency (HCC + LDSD) were induced by squeezing tails (30 min/day), solitary breeding and intermittent fasting on the basis of HCC; XCHD was administered after 4 weeks of the HCC + LDSD. The degree of tissue injury were studied using a scoring system, and brain weights were measured. Peroxynitrite $\left(\mathrm{ONOO}^{-}\right)$, malondialdehyde (MDA), 4-hydroxy-3-methoxymandelic acid (VMA, CA metabolites), lipopolysaccharide-phosphate (LPS-P), ALP activity (ALP-A) and Concanavalin A (ConA)-binding rate of ALP (ALP-C) were determined by colorimetric method and lectin (ConA) affinity precipitation method.

Results: More injuries and ONOO-, MDA, VMA, LPS-P, ALP-C were increased, ALP-A were decreased in the gut, liver and brain of HCC group, the most in HCC + LDSD group, after treatment with XCHD, all of which were improved. A positive association found between gut-liver-brain injury and ONOO-, MDA, VMA, LPS-P, ALP-C, between ONOO-', MDA, VMA, LPS-P and ALP-C in the gut, liver and brain, and a negative association found between gut-liver-brain injury and ALP-A, between ALP-A and ONOO-, MDA, VMA, LPS-P, ALP-C in the gut, liver and brain.

Conclusions: XCHD can attenuates the vicious circle between the oxidative stress, nitrosative stress, N-glycan deficiency and inactivation of ALP through LPS-CA interactions in gut, liver and brain.

Keywords: Xiaochaihu Decoction (XCHD), Ethanol, $\mathrm{CCl}_{4}$, Hepatocellular carcinoma (HCC), Liver depression and spleen deficiency (LDSD), Oxidative stress, Nitrosative stress, Lipopolysaccharid, Catecholamines,

Alkaline phosphatase (ALP)

\footnotetext{
* Correspondence: Ixq@gzucm.edu.cn

${ }^{1}$ Piwei Research Institutes, Guangzhou University of Chinese Medicine,

Guangzhou 510405, Guangdong, China

Full list of author information is available at the end of the article
} 


\section{Background}

The applications of XCHD in treatment of tumors have attracted more and more attention. XCHD helped to prevent the development of HCC in patients with cirrhosis, particularly in patients without HBs antigen [1], Shiota et al. found that XCHD (TJ-9) reduced the number of preneoplastic cells, inhibited the development of liver tumors, and significantly decreased the formation of 8-hydroxy-2'-deoxyguanosine (8-OHdG), they concluded that XCHD prevents hepatocarcinogenesis in association with inhibition of 8-OHdG formation [2], but few literature covers this field of the efficacy of the XCHD by affecting multiple organ systems.

There is a strong relationship between liver injury and gut injury by portal system and endogenous gut-derived bacterial lipopolysaccharides (LPS), which induces production of catecholamines (CA) in the gut-liver-brain, which are involved in the neuroendocrine and immune effects of LPS, and also contributes to the sensitizing effect of ethanol preexposure on LPS-induced gut-liverbrain damage and ultimately, to the LPS-CA interactions promote hepatocellular carcinoma development [3-9], its mechanism is still unknown.

Main symptoms for the pattern of LDSD are mental depression, sentiment, fatigue, reddish or pale tongue, reduced food intake, fine or fine stringlike pulse.

LDSD has already become common traditional Chinese medicine (TCM) syndrome pattern in clinical, especially in chronic hepatopathy such as chronic hepatitis, cirrhosis and hepatocarcinoma. Chronic stress or depression (squeezing tails, solitary breeding and intermittent fasting) is often used to induce LDSD.

We examined whether XCHD attenuates the vicious circle between the oxidative stress and the ALP inactivation through LPS-CA interactions in gut, liver and brain during $\mathrm{CCI}_{4}$ + ethanol-induced mouse $\mathrm{HCC}$ with LDSD.

\section{Methods}

Ethics

This study was approved by Guangdong Science and Technology Committee and Guangdong Management Committee for Medical Experimental Animals.

\section{General procedure}

Chinese Kun Ming (KM) mouse were obtained from the Laboratory Animal Research Center of Guangzhou University of Traditional Chinese Medicine. The animals were housed in a plastic cage in an air-conditioned room at $20 \pm 2{ }^{\circ} \mathrm{C}$ with a humidity $58 \% \pm 5 \%$ in a 12 -h light and dark cycle with free access to standard rat food and tap water.

\section{Animals model}

A total of 80 male KM mice (cleaning grade, 30 days of age, 18-22 g) were used. The KM mouse were divided into four groups, normal group (10 mice), Hepatocellular carcinoma group (HCC,30 mice), were induced as previously described [10] with some minor modifications by subcutaneously injected with $25 \% \mathrm{CCI}_{4}$ olive oil solution $(5 \mathrm{~mL} / \mathrm{kg}$ twice per week) and allowed free access to a $8 \%$ ethanol solution as drinking fluid for 4 weeks, and allowed free access to a $0.5 \% \mathrm{CCI}_{4}-8 \%$ ethanol solution as drinking fluid for 20 weeks; HCC + LDSD group (HCC + LDSD, 30 mice), on the basis of HCC model, the mouse were stimulated with the factor of Liver Depression with Spleen Deficiency (LDSD): squeezing tails (30 min/day) for 4 weeks, solitary breeding and intermittent fasting for 20 weeks; HCC + LDSD + XCHD group (XCHD, 30 mice), XCHD was administered by gavage for 8 weeks after 4 weeks of the HCC + LDSD. We recommend 30 mice/model group, this relatively large number of mice is recommended to ensure that enough mice for good statistical analysis, tumor models process often leads to the incidental death of mice.

\section{Preperation and administration of XCHD}

The XCHD consisting of seven herbal medicines (Table 1) and each crude drug was purchased from Hexiang Pharmaceutical Co., Ltd., China. The origin of materials was confirmed and standardized taxonomically by the Traditional Chinese Medicine Herbal Pharmacy, Guangzhou University of TCM. A decoction of XCHD was prepared in our laboratory (Table 1) from a mixture of chopped crude herbs, extracted in distilled water at $100^{\circ} \mathrm{C}$, this mixture was then concentrated to a final concentration of 100 crude drug gram per 100 milliliter, was administered by gavage, $8 \mathrm{~g} / \mathrm{kg}$ per day for 8 weeks, was dried out $(3.34 \mathrm{~g})$ in hot $\left(100^{\circ} \mathrm{C}\right)$ water bath for quantitative assay of saikosaponin a of the major constituents in $\mathrm{XCHD}$, the procedure is as follows.

\section{Quantitative assay of saikosaponin a of the major constituents in XCHD [11,12] Linearity and limits of detection of Saikosaponin a}

Standard stock solutions of Saikosaponin a were dissolved in $70 \%$ methanol containing $0.1 \mathrm{~N}$ sulfate acid and stored below $4^{\circ} \mathrm{C}$. Working standard solutions were prepared by serial dilution of stock solutions with $70 \%$ methanol containing $0.1 \mathrm{~N}$ sulfate acid, heated at $100^{\circ} \mathrm{C}$ for $3 \mathrm{~h}$, Saikosaponin a were converted completely into saikosaponin b by mild acid treatment, the absorbance of Saikosaponin b was detected by UV-spectrophotometer at $252 \mathrm{~nm}$. Calibration curves of Saikosaponin a were calculated by the absorbance of standard solutions in the concentration of $0-200.00 \mu \mathrm{g} / \mathrm{mL}$.

\section{Quantitative assay of saikosaponin a in XCHD}

Freeze-dried XCHD were prepared with $70 \%$ methanol containing $0.1 \mathrm{~N}$ sulfate acid, heated at $100^{\circ} \mathrm{C}$ for $3 \mathrm{~h}$, 
Table 1 The composition of XCHD

\begin{tabular}{|c|c|c|c|}
\hline Latin name & Amount (g) & Company of purchased & Source \\
\hline Chai Hu (Radix Bupleuri) & 20 & Hexiang Pharmaceutical Co., Ltd & China \\
\hline Huang Qin (Radix Scutellariae baicalensis) & 10 & Hexiang Pharmaceutical Co., Ltd & China \\
\hline Dangshen (Codonopsis pilosula) & 10 & Hexiang Pharmaceutical Co., Ltd & China \\
\hline Ban Xia (Rhizoma Pinelliae Tematae) & 10 & Hexiang Pharmaceutical Co., Ltd & China \\
\hline Gan Cao (Radix Glycyrhizae Uralensis) & 5 & Hexiang Pharmaceutical Co., Ltd & China \\
\hline Gan jian (Rhizoma Zingiberis) & 5 & Hexiang Pharmaceutical Co., Ltd & China \\
\hline Da Zao (Fruc-tus Zizyphi Jujubae) & 6 & Hexiang Pharmaceutical Co., Ltd & China \\
\hline Total & 66 & & \\
\hline
\end{tabular}

Saikosaponin a were converted completely into saikosaponin b by mild acid treatment, the absorbance of Saikosaponin b was detected by UV-spectrophotometer at $252 \mathrm{~nm}$. The amount of Saikosaponin a in XCHD was quantified using the calibration curves of the above-mentioned Saikosaponin a.

\section{Stability of saikosaponin a in XCHD}

The stabilities of Saikosaponin a was examined for 6 days $(0,1,2,3,4$ and 5 day respectively) by three sample solution.

\section{Anatomic analysis}

Every mouse were autopsied as quickly as possible after natural death and killed, and photographed, and liver were embedded in paraffin and stained with hematoxylin and eosin. The extent of macroscopically apparent inflammation ulceration and tissue injury was done unblinded by two examiners using a scoring system. This tissue was weighed, processed and the resulting supernatant stored at $-20^{\circ} \mathrm{C}$ for the subsequent determination of $\mathrm{ONOO}^{-}$, MDA, VMA, ALP-A, for the assay of ALP$\mathrm{C}$ or for the assay of LPS-P.

\section{Macroscopic score of gut damage}

Intestine macroscopic damage score was calculated as previously described [13] with some minor modifications and graded as $0=$ no apparent damage, $1=$ slight thickening of intestinal wall, redness, 2 =thickening and adhesions, no apparent ulcers, $3=$ adhesions and one or more pin-point ulcers, $4=$ adhesions and pinpoint ulcers with one or more linear ulcer $<1 \mathrm{~cm}$ in length, $5=$ one or more linear ulcer $>1 \mathrm{~cm}$ in length.

\section{Macroscopic score of fecal loading in the cecum}

Fecal loading in the cecum was graded as $0=$ no fecal loading in the cecum, 1 = mild fecal loading in the cecum, 2 =moderate fecal loading in the cecum, $3=$ marked fecal loading in the cecum.

\section{Macroscopic score of liver damage}

Iiver macroscopic damage score was graded as $0=$ reddish brown in color, soft in consistency, smooth surface, $1=$ the liver were enlarged, friable, soft in consistency, $2=$ hepatic hyperemia, 3 = an enlarged liver with white focal areas of necrosis, $4=$ an enlarged liver with white multifocal areas of necrosis, 5 = hepatic steatosis, the liver were soft, yellow, greasy, enlarged, $6=$ the liver is mottled red with bile stained areas, of normal or increased size, $7=$ contains visible nodules and fibrosis, $8=$ micronodular, yellow, fatty, enlarged, 9 = macronodular, brown, non-greasy, shrunken, cirrhosis, $10=$ explanted liver showing small single granules bodies, 11 = explanted liver showing large single granules bodies, 12 =xplanted liver showing many small granules bodies, $13=$ explanted liver showing many large granules bodies.

\section{ALP-A and ALP-C in the tissue}

Extracts from tissue were prepared by homogenization in $9 \mathrm{~g} / \mathrm{L} \mathrm{NaCl}$ at $4^{\circ} \mathrm{C}$ using a DY89-1 tissue homogenizer. Tissue homogenate was centrifuged at $10000 \mathrm{r} / \mathrm{min}$ for $30 \mathrm{~min}$. Clear supernatant were used to determine the ALP-A and ALP-C by lectin (ConA) affinity precipitation method, the precipitation procedure was performed as previously described $[14,15]$. The clear supernatant were mixed with $400 \mu \mathrm{L}$ of an aqueous solution of Con ASepharose 6B (5 g/L in distilled water). The mixture was incubated for $30 \mathrm{~min}$ at $37^{\circ} \mathrm{C}$ and centrifuged at $2000 \mathrm{r} / \mathrm{min}$ for $15 \mathrm{~min}$. Without disturbing the precipitate, we removed the supernate and measured its ALPA. ALP-C was calculated by subtracting the corrected value from the total ALP-A, ALP-A was measured with $\beta$-glycerophosphate as substrate.

\section{The $\mathrm{ONOO}^{-}$levels in the tissue}

The tissue were initially deproteinized with Somogyi reagent [16] (using $2.0 \mathrm{ml} 55 \mathrm{mmol} / \mathrm{L} \mathrm{NaOH}$ followed by $2.0 \mathrm{ml} 75 \mathrm{mmol} / \mathrm{L} \mathrm{ZnSO}_{4}$ ), after centrifugation, aliquots of supernatant $\mathrm{ONOO}^{-}$concentration was measured from its absorption at $302 \mathrm{~nm}$ by using $\varepsilon_{302}=1670 \mathrm{~mol} \cdot \mathrm{L}^{-1} \cdot \mathrm{cm}^{-1}$ [17]. Results were expressed as nmol/L per gram wet tissue. 


\section{The MDA levels in the tissue}

Samples were weighed and immediately frozen and stored at $-20^{\circ} \mathrm{C}$ until analysis within 2 wk. Samples were subsequently homogenized in buffer and assayed for MDA content using the thiobarbituric acid (TBA) reaction, as described by Uchiyama and Mihara [18]. with some minor modifications. Briefly, $0.5 \mathrm{~mL}$ of homogenate (10\% concentration) was mixed with $3 \mathrm{~mL}$ of $0.05 \mathrm{~N}$ HCL. After addition of $1 \mathrm{~mL}$ of $0.67 \%$ TBA reagent, the tubes were heated in boiling water for $45 \mathrm{~min}$. The color was formed with $4 \mathrm{~mL}$ of $\mathrm{n}$-butanol and centrifuged. The color intensity of the butanol layer was estimated by spectrophotometric absorbance at $535 \mathrm{~nm}$. Results were expressed as $\mathrm{pmol} / \mathrm{L}$ per gram wet tissue.

\section{LPS-P levels in the tissue}

The protocol was performed as previously described $[19,20]$ with the following modifications. Lipopolysaccharide was extracted by the hot phenol/water procedure. The polysaccharide moiety was separated from the lipid A by hydrolysis of lipopolysaccharide in $10 \%$ acetic acid at $100^{\circ} \mathrm{C}$ for $2.5-4 \mathrm{~h}$. After in separation of lipid A by centrifugation at $1300 \mathrm{x} \mathrm{g}$ for $15 \mathrm{~min}$, the lipid A was washed twice with warm water $\left(70-80^{\circ} \mathrm{C}\right)$ and once with acetone. Degraded polysaccharide, obtained from the supernatant fluid, was purified by centrifugation $(10500 \times \mathrm{g}, 3 \mathrm{~h})$ and the supernatant was lyophilized, the phosphate content of LPS was determined with phosphomolybdate-blue spectrophotometry. The amount of inorganic phosphate was quantified using the phosphate standard curve, which was obtained by using serial dilutions of $1.00 \mathrm{mM} \mathrm{KH_{2 }} \mathrm{PO}_{4}$ standard solution.

\section{VMA levels in the tissue}

The protocol was performed as previously described [21] with the following modifications. VMA is extracted by ethyl acetate, is oxidised with periodic acid to vanillin, and the coloured hydrazone formed from the oxidation product and added 2,4-dinitrophenylhydrazine is measured in alkali at $460 \mathrm{~nm}$. The amount of VMA was quantified using the vanillin standard curve, which was obtained by using serial dilutions of $250 \mathrm{ug} / \mathrm{ml}$ vanillin standard solution.

\section{Statistical analysis}

Quantitative differences in ONOO-, MDA, VMA, LPSP, ALP-A, ALP-C between Normal, HCC, HCC + LDSD and XCHD were evaluated with the unpaired Student's $T$-test. We evaluated quantitative correlations between the variables with the spearman rank correlation test. $\mathrm{P}$ values $<0.05$ were considered statistically significant. All analyses were performed using SPSS 17.

\section{Results}

Linearity and range of detection of saikosaponin a

The linearity of the absorbance at $252 \mathrm{~nm} \mathrm{(x)} \mathrm{versus}$ concentration $(y, \mu g / m L)$ curve for Saikosaponin a was used to calculate the contents of the main components Saikosaponin a in XCHD. The correlation coefficients(R) of the calibration curves were 0.9985 . The regression equations were $\mathrm{Y}=369.82 \times-2.071$ for Saikosaponin a. These results showed that the calibration curve was a good linearity.

\section{Stability of saikosaponin a in XCHD}

The stability test of Saikosaponin a was evaluated using the sample solution for 6 days. In Table 2, sample solution retained a content of $76.92-100.88 \%$ as compared with the initial content at 0 day. The RSD values of contents about saikosaponin a compounds in sample solution were with in $15.52 \%$.

\section{Histological and anatomic analysis}

During chemical induction of hepatic cancer by $\mathrm{CCI}_{4}+$ ethanol, Histological examination of liver sections by $\mathrm{H} \& \mathrm{E}$ staining showed that the induction of hepatic cancer involves four stages: stage 1 , hepatic steatosis occurred at 5 to 8 weeks during hepatic carcinoma induction; stage 2 , hepatic cirrhosis occurred at 9 to 12 weeks during hepatic carcinoma induction; stage 3 , precancerous Lesion of Liver occurred at 13 to 16 weeks during hepatic carcinoma induction; stage 4 , hepatic carcinoma occurred at 17 to 24 weeks during hepatic carcinoma induction (Figure 1).

HCC group were significantly more deep red color of liver, the surface of the liver is granular and nodular, a more disordered structure of hepatic lobule, the hepatic cell nuclear anachromasis with nuclear atypia in the $\mathrm{H} \& \mathrm{E}$ stained section. HCC + LDSD group were significantly more dark red color of liver, the surface of the liver is granular and nodular, a more disordered structure of hepatic lobule, the hepatic cell nuclear anachromasis with nuclear atypia in the H\&E stained section.

Significantly more injuries in small intestine, cecum, liver(mainly hyperplasia) of HCC, only a slight nonsignificant reduction was observed in brain weights, compared with normal group, the most in HCC + LDSD group, compared with HCC group, after treatment with $\mathrm{XCHD}$, all of which were improved, compared with HCC + LDSD group. The other organs do not show obvious macroscopic damage (Table 3 ).

\section{Effects of XCHD on MDA, ONOO-, VMA, LPS-P, ALP-A, $A L P-C$ in the gut, liver and brain}

$\mathrm{ONOO}^{-}, \mathrm{MDA}, \mathrm{VMA}, \mathrm{LPS}-\mathrm{P}, \mathrm{ALP}-\mathrm{C}$ were increased, ALP-A were decreased in the gut, liver and brain of HCC group, compared with normal group, the most in $\mathrm{HCC}+$ 
Table 2 Stability of saikosaponin a compounds for 6 days XCHD $(n=3)$

\begin{tabular}{|c|c|c|c|c|c|c|c|c|c|c|c|c|}
\hline \multirow[t]{2}{*}{ Compounds } & \multicolumn{2}{|c|}{0 day } & \multicolumn{2}{|c|}{1 day } & \multicolumn{2}{|c|}{2 day } & \multicolumn{2}{|c|}{3 day } & \multicolumn{2}{|c|}{4 day } & \multicolumn{2}{|c|}{5 day } \\
\hline & $\begin{array}{c}\operatorname{mean} \pm S D \\
(\mathrm{mg} / \mathrm{g})\end{array}$ & $\begin{array}{l}\text { RSD } \\
(\%)\end{array}$ & $\begin{array}{c}\operatorname{mean} \pm S D \\
(\mathrm{mg} / \mathrm{g})\end{array}$ & $\begin{array}{l}\text { RSD } \\
(\%)\end{array}$ & $\begin{array}{c}\operatorname{mean} \pm S D \\
(\mathrm{mg} / \mathrm{g})\end{array}$ & $\begin{array}{c}\text { RSD } \\
(\%)\end{array}$ & $\begin{array}{c}\operatorname{mean} \pm S D \\
(\mathrm{mg} / \mathrm{g})\end{array}$ & $\begin{array}{c}\text { RSD } \\
(\%)\end{array}$ & $\begin{array}{c}\operatorname{mean} \pm S D \\
(\mathrm{mg} / \mathrm{g})\end{array}$ & $\begin{array}{l}\text { RSD } \\
(\%)\end{array}$ & $\begin{array}{c}\operatorname{mean} \pm S D \\
(\mathrm{mg} / \mathrm{g})\end{array}$ & $\begin{array}{c}\text { RSD } \\
(\%)\end{array}$ \\
\hline Saikosaponin & $0.14 \pm 0.03$ & 2.19 & $0.14 \pm 0.02$ & 1.38 & $0.14 \pm 0.01$ & 7.85 & $0.12 \pm 0.08$ & 6.77 & $0.12 \pm 0.09$ & 7.99 & $0.11 \pm 0.16$ & 15.52 \\
\hline
\end{tabular}

LDSD group, compared with HCC group, after treatment with XCHD, all of which were improved, compared with HCC + LDSD group (Table 4).

The correlation coefficient between gut injuries, liver injuries, brain injuries, MDA, ONOO- ${ }^{-}$VMA, LPS-P, ALP, ALP-C

Correlative analysis showed that there was a positive association between gut-liver-brain injury and $\mathrm{ONOO}^{-}$, MDA, VMA, LPS-P, ALP-C, between $\mathrm{ONOO}^{-}$, MDA, VMA, LPS-P and ALP-C in the gut, liver and brain, there was a negative association between gut-liver-brain injury and ALP-A, between ALP-A and ONOO- ${ }^{-}$MDA, VMA, LPS-P, ALP-C in the gut, liver and brain (Tables 5, 6, 7 and 8).

\section{Discussion}

In our present study, more injuries and $\mathrm{ONOO}^{-}, \mathrm{MDA}$, VMA, LPS-P, ALP-C were increased, ALP-A were decreased in the gut, liver and brain of HCC group, compared with normal group, the most in HCC with Liver Depression and Spleen Deficiency(LDSD) group, compared with HCC group, after treatment with XCHD, all of which were improved, compared with HCC + LDSD group (Tables 3 and 4). A positive association found between gut-liver-brain injury and $\mathrm{ONOO}^{-}, \mathrm{MDA}, \mathrm{VMA}$, LPS-P, ALP-C, between ONOO ${ }^{-}$, MDA, VMA, LPS-P, ALP-C, and a negative association found between gutliver-brain injury and ALP-A, between ALP-A and $\mathrm{ONOO}^{-}, \mathrm{MDA}, \mathrm{VMA}, \mathrm{LPS}-\mathrm{P}, \mathrm{ALP}-\mathrm{C}$ in the gut, liver and brain (Tables 5, 6, 7 and 8).
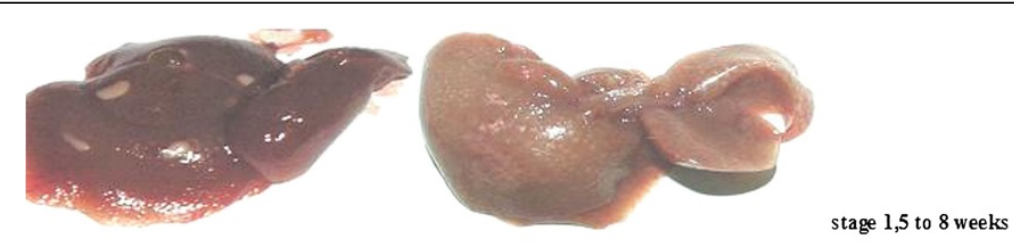

(left 5 weeks, right 8 weeks)
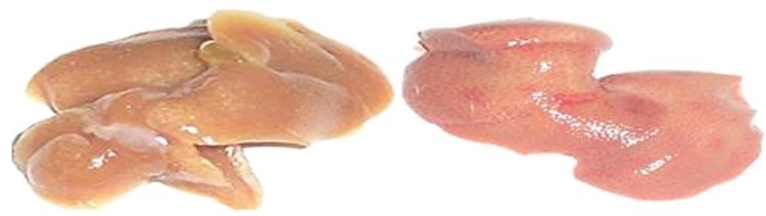

stage 29 to 12 weeks

(left 9 weeks, right 12 weeks)
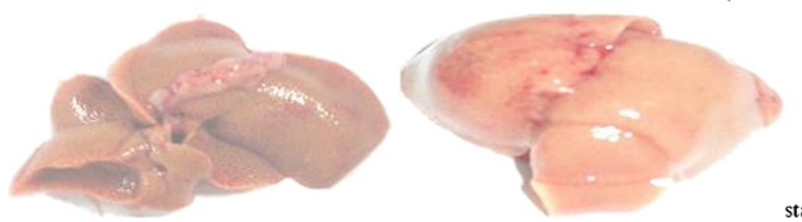

stage 3,13 to 16 weeks

(left 13 weeks, right 16 weeks)
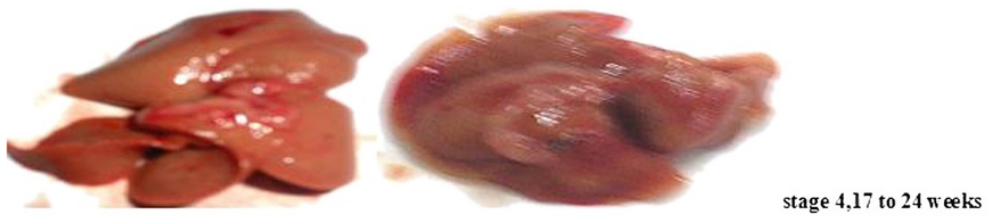

(left 17 weeks, right 24 weeks)

Figure $1 \mathrm{CCl}_{4}$ + ethanol-induced hepatocellular carcinoma ( $\mathrm{HCC}$ ) Chinese Kun Ming (KM) mouse were treated with $\mathrm{CCl}_{4}+$ ethanol and autopsied after natural death and killed. Histological examination of liver sections by H\&E staining showed that the induction of hepatic cancer involves four stages: stage 1, hepatic steatosis occurred at 5 to 8 weeks; stage 2: hepatic cirrhosis occurred at 9 to 12 weeks; stage 3, hepatic precancerous lesion occurred at 13 to 16 weeks; stage 4, hepatic carcinoma occurred at 17 to 24 weeks. Photomacrographs are liver representative of at least two observations. 
Table 3 Effect of XCHD on macrospic gut-liver injury and brain weights

\begin{tabular}{lllllllll}
\hline Groups & Dose $\left(\mathbf{g k g}^{-\mathbf{1}}\right)$ & $\mathbf{n}$ & $\begin{array}{l}\text { Intestine } \\
\text { injury score }\end{array}$ & Cecum injury score & $\begin{array}{l}\text { Fecal loading in } \\
\text { the cecum (score) }\end{array}$ & Colore injury score & $\begin{array}{l}\text { Liver injury score } \\
\text { Brain } \\
\text { weights (g) }\end{array}$ \\
\hline Normal & - & 6 & $0.5 \pm 0.55$ & $0.67 \pm 0.52$ & $0.67 \pm 0.52$ & $0.33 \pm 0.52$ & $0.5 \pm 0.55$ & $0.44 \pm 0.04$ \\
HCC & - & 13 & $1.77 \pm 0.73^{\mathrm{b}}$ & $1.62 \pm 0.51^{\mathrm{b}}$ & $1.15 \pm 0.69$ & $0.46 \pm 0.52$ & $9.15 \pm 2.08^{\mathrm{b}}$ & $0.43 \pm 0.04$ \\
$\mathrm{HCC}+$ LDSD & - & 9 & $2.33 \pm 0.50^{\mathrm{c}}$ & $2.33 \pm 0.71^{\mathrm{c}}$ & $1.44 \pm 0.73$ & $0.56 \pm 0.53$ & $10.67 \pm 1.80^{\mathrm{c}}$ & $0.39 \pm 0.06$ \\
$\mathrm{XCHD}$ & 8 & 14 & $1.57 \pm 0.52^{\mathrm{f}}$ & $1.50 \pm 0.52^{\mathrm{f}}$ & $1.33 \pm 0.52$ & $0.43 \pm 0.51$ & $8.21 \pm 2.08^{\mathrm{f}}$ & $0.43 \pm 0.05$ \\
\hline
\end{tabular}

${ }^{\mathrm{b}}<0.01$ Compare with normal; ${ }^{\mathrm{C} P}<0.05$ Compare with $\mathrm{HCC}^{\mathrm{f}}<0.01$ Compare with HCC+ LDSD.

Yu LX et al. [7] found endotoxin accumulation prevents carcinogen-induced apoptosis and promotes liver tumorigenesis. Zhou L et al. [22] and Tang $\mathrm{CH}$ et al. [23] found oxidative stress-induced 1, N6-ethenodeoxyadenosine adduct formation and uncontrolled nitrosative stress contributes to hepatocarcinogenesis. Xiang Q et al. [24] found LPS-induced hepatotoxicity possibly by cytotoxic effects of oxygen free radicals, NO and cytokines, carnosic acid successfully and dose dependently attenuates the effects of LPS.von Montfort C et al. [5] found the

Table 4 Effects of XCHD on MDA, ONOO-, VMA, LPS-P, ALP-A and ALP-C in the gut, liver and brain

\begin{tabular}{|c|c|c|c|c|}
\hline Groups & Dose (g.kg-1) & Gut (n) & Liver $(\mathrm{n})$ & Brain (n) \\
\hline \multicolumn{5}{|c|}{ MDA (nmol/L/g) } \\
\hline Normal & - & $5.48 \pm 1.78(6)$ & $300.86 \pm 29.16(6)$ & $68.34 \pm 13.22(6)$ \\
\hline $\mathrm{HCC}$ & - & $62.75 \pm 19.80(9)^{\mathrm{b}}$ & $318.21 \pm 23.27(6)$ & $126.39 \pm 30.92(8)^{b}$ \\
\hline $\mathrm{HCC}+\mathrm{LDSD}$ & - & $171.67 \pm 42.24^{d}$ & $360.87 \pm 48.02(6)^{c}$ & $180.72 \pm 27.05(8)^{d}$ \\
\hline $\mathrm{XCHD}$ & 8 & $58.69 \pm 17.99^{f}$ & $319.75 \pm 19.28(7)$ & $127.06 \pm 24.33(8)$ \\
\hline \multicolumn{5}{|c|}{$\mathrm{ONOO}^{-}(\mathrm{mmol} / \mathrm{L} / \mathrm{g})$} \\
\hline Normal & - & $7.39 \pm 0.66(6)$ & $12.87 \pm 0.95(6)$ & $3.99 \pm 24.33(8)^{f}$ \\
\hline $\mathrm{HCC}$ & - & $10.61 \pm 0.85(13)^{b}$ & $16.40 \pm 0.80(13)^{b}$ & $7.46 \pm 1.42(13)^{b}$ \\
\hline $\mathrm{HCC}+\mathrm{LDSD}$ & - & $15.19 \pm 1.78(9)$ & $19.86 \pm 0.80(9)$ & $12.90 \pm 0.48(9)^{d}$ \\
\hline XCHD & 8 & $10.31 \pm 1.12(14)^{f}$ & $14.15 \pm 0.92(9)$ & $12.90 \pm 0.48(9)$ \\
\hline \multicolumn{5}{|c|}{ VMA (ug/ml/g) } \\
\hline Normal & - & $6.78 \pm 1.09(6)$ & $32.46 \pm 5.64(6)$ & $1.76 \pm 0.96(6)$ \\
\hline $\mathrm{HCC}$ & - & $9.94 \pm 0.10^{\mathrm{b}}$ & $51.01 \pm 5.06(9)^{b}$ & $3.99 \pm 0.46(6)^{b}$ \\
\hline HCC+LDSD & - & $19.79 \pm 0.28(6)^{d}$ & $86.66 \pm 5.06(9) d$ & $11.81 \pm 6.60(6)^{c}$ \\
\hline $\mathrm{XCHD}$ & 8 & $10.52 \pm 0.56(6)^{b}$ & $74.38 \pm 10.20(14)^{f}$ & $2.92 \pm 2.82(6)^{f}$ \\
\hline \multicolumn{5}{|c|}{ LPS-P (mmol/L/g) } \\
\hline Normal & - & $0.55 \pm 0.04(6)$ & $0.36 \pm 0.11(6)$ & $0.052 \pm 0.003(6)$ \\
\hline $\mathrm{HCC}$ & - & $0.66 \pm 0.06(6)^{b}$ & $0.86 \pm 0.09(13)^{b}$ & $0.060 \pm 0.004(6)^{b}$ \\
\hline HCC+LDSD & - & $0.76 \pm 0.06(6)^{d}$ & $1.30 \pm 0.43(6)^{d}$ & $0.075 \pm 0.003(6)^{d}$ \\
\hline $\mathrm{XCHD}$ & 8 & $0.57 \pm 0.05(6)^{f}$ & $0.71 \pm 0.12(14)^{f}$ & $0.059 \pm 0.009(6)^{f}$ \\
\hline \multicolumn{5}{|l|}{ ALP-A $(\mu)$} \\
\hline Normal & - & $131.98 \pm 30.86(6)$ & $140.17 \pm 8.74(6)$ & $29.60 \pm 2.41(6)$ \\
\hline $\mathrm{HCC}$ & - & $55.52 \pm 8.87(6)^{b}$ & $53.70 \pm 7.78(6)^{b}$ & $27.75 \pm 4.66(6)^{b}$ \\
\hline HCC+LDSD & - & $35.94 \pm 8.77(6)^{d}$ & $38.73 \pm 7.78(6)^{d}$ & $20.27 \pm \pm 4.65(6)^{d}$ \\
\hline $\mathrm{XCHD}$ & 8 & $94.16 \pm 12.35(6)^{f}$ & $64.13 \pm 7.52(6)^{f}$ & $39.37 \pm 6.12(6)^{f}$ \\
\hline \multicolumn{5}{|l|}{ ALP-C (\%) } \\
\hline Normal & - & $8.69 \pm 3.75(6)$ & $10.01 \pm 1.24(6)$ & 26.06.70(6) \\
\hline $\mathrm{HCC}$ & - & $47.32 \pm 14.75(6)^{b}$ & $56.89 \pm 9.98(6)^{b}$ & $37.84 \pm 6.95(6)^{b}$ \\
\hline $\mathrm{HCC}+\mathrm{LDSD}$ & - & $78.47 \pm 18.41(6)^{d}$ & $75.37 \pm 14.87(6)^{c}$ & $80.0 \pm 5.28(6)^{d}$ \\
\hline$X C H D$ & 8 & $20.73 \pm 4.82(6) f$ & $32.73 \pm 4.49(6)^{f}$ & $45.73 \pm 11.43(6)$ \\
\hline
\end{tabular}

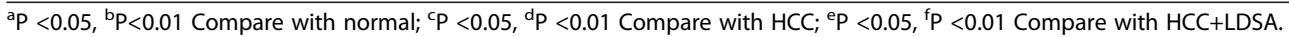


Table 5 The correlation coefficient between gut injury, liver injury, brain injury, MDA, ONOO, CMA, LPS-P, ALP-A and ALP-C in the gut

\begin{tabular}{|c|c|c|c|c|c|c|c|}
\hline & $\mathbf{n}$ & ALP-A & ALP-C & MDA & ONOO & LPS-P & VMA \\
\hline ALP-A & 24 & & $-0.68^{b}$ & $-0.79^{b}$ & $-0.78^{b}$ & $-0.71^{b}$ & $-0.71^{\mathrm{b}}$ \\
\hline ALP-C & 24 & & & $0.49^{b}$ & $0.57^{b}$ & $0.63^{b}$ & $0.59^{b}$ \\
\hline MDA & 24 & & & & $0.94^{\mathrm{b}}$ & $0.73^{b}$ & $0.92^{b}$ \\
\hline $\mathrm{ONOO}^{-}$ & 24 & & & & & $0.70^{\mathrm{b}}$ & $0.91^{\mathrm{b}}$ \\
\hline LPS-P & 24 & & & & & & $0.79^{b}$ \\
\hline Intestine & 24 & $-0.87^{b}$ & $0.56^{\mathrm{b}}$ & $0.78^{b}$ & $0.80^{\mathrm{b}}$ & $0.64^{b}$ & $0.69^{b}$ \\
\hline Cecum injury & 24 & $-0.60^{b}$ & $0.66^{\mathrm{b}}$ & $0.53^{b}$ & $0.63^{b}$ & $0.63^{b}$ & $0.66^{\mathrm{b}}$ \\
\hline Fecal loading in the cecum & 24 & $-0.60^{b}$ & $0.66^{\mathrm{b}}$ & $0.53^{\mathrm{b}}$ & $0.63^{b}$ & $0.63^{b}$ & 0.26 \\
\hline Colorectal injury & 24 & 0.03 & 0.20 & 0.01 & 0.02 & 0.25 & 0.17 \\
\hline Liver injury & 24 & $-0.80^{b}$ & $0.68^{b}$ & $0.68^{b}$ & $0.73^{b}$ & $0.54^{\mathrm{b}}$ & $0.63^{b}$ \\
\hline Brain weights & 24 & $0.46^{\mathrm{a}}$ & $-0.42^{\mathrm{a}}$ & $-0.52^{b}$ & $-0.41^{\mathrm{a}}$ & $-0.53^{b}$ & $0.55^{\mathrm{b}}$ \\
\hline
\end{tabular}

${ }^{\mathrm{a}} \mathrm{P}<0.05,{ }^{\mathrm{b}} \mathrm{P}<0.01$, test of significance of correlation coefficient.

sympathetic hormone epinephrine preexposure enhances LPS-induced liver damage. Schäper J et al. [25] found Regional sympathetic blockade significantly attenuated the endotoxin-induced increases in gut epithelial permeability, expression of nitric oxide synthase, macrophage infiltration, and lipid peroxidation. Adham KG et al. [26] found lipopolysaccharide stimulated the biosynthesis of norepinephrine and dopamine in all brain regions, was completely abolished by pretreatment with indomethacin.

The toxic moiety of Lipopolysaccharide (LPS) is the well-preserved lipid A part. Lipid A contains two phosphate groups attached to diglucosamine, which are crucial for the many biological activities of LPS [27]. Radiodetoxified lipopolysaccharide fails to activate the hypophysealpituitary-adrenal axis [28] and alkaline Phosphatase (ALP) was able to dephosphorylate LPS and prevents inflammation [29].
ALP are important defense factor in protecting the gut-liver-brain multiple organ against bacterial infection [30-32]. Halling Linder C et al. [33] found significantly different catalytic properties among the bone ALP isoforms due to structural differences in N-glycosylation. The changes in protein $\mathrm{N}$-glycosylation play an important role in the pathogenesis and progression of various liver diseases [34]. Cottalasso D et al. [35] found ethanol administration induces a marked decrease of dolichyl phosphate (a glycosyl sugar carrier for N-glycosylation of proteins) in rat liver microsomes and Golgi apparatus. Yasuda J et al. [36] found ROS result in the cleavage of oligosaccharides of glycoproteins including transferrin may contribute the development of acute hepatitis.

We had previously found [14] that ConA, PSA, PNA, and LCA binding rate of serum amylase were significantly higher in HCC and hepatocirrhosis patients than hepatitis patients and normal controls. PSA and LCA

Table 6 The correlation coefficient between gut injury, liver injury, brain injury, MDA, ONOO-, VMA, LPS-P, ALP-A and ALP-C in the liver

\begin{tabular}{|c|c|c|c|c|c|c|c|}
\hline & $\mathrm{n}$ & ALP-A & ALP-C & MDA & ONOO & LPS-P & VMA \\
\hline ALP-A & 24 & & $-0.86^{\mathrm{b}}$ & $-0.42^{\mathrm{a}}$ & $-0.68^{b}$ & $-0.75^{b}$ & $-0.83^{b}$ \\
\hline ALP-C & 24 & & & $0.40^{\mathrm{a}}$ & $0.60^{\mathrm{b}}$ & $0.74^{\mathrm{b}}$ & $0.65^{\mathrm{b}}$ \\
\hline MDA & 24 & & & & $0.51^{\mathrm{b}}$ & $0.44^{\mathrm{a}}$ & $0.60^{\mathrm{b}}$ \\
\hline $\mathrm{ONOO}^{-}$ & 24 & & & & & $0.63^{\mathrm{b}}$ & $0.80^{\mathrm{b}}$ \\
\hline LPS-P & 24 & & & & & & $0.71^{b}$ \\
\hline Intestine & 24 & $-0.80^{b}$ & $0.80^{\mathrm{b}}$ & $0.50^{\mathrm{b}}$ & $0.70^{\mathrm{b}}$ & $0.63^{\mathrm{b}}$ & $0.73^{b}$ \\
\hline Cecum injury & 24 & $-0.65^{b}$ & $0.51^{\mathrm{b}}$ & 0.30 & $0.60^{\mathrm{b}}$ & 0.34 & 0.76 \\
\hline Fecal loading in the cecum & 24 & -0.33 & 0.32 & 0.24 & 0.17 & $0.40^{\mathrm{a}}$ & $0.36^{\mathrm{a}}$ \\
\hline Colorectal injury & 24 & -0.09 & -0.32 & 0.02 & 0.18 & -0.11 & 0.17 \\
\hline Liver injury & 24 & $-0.94^{b}$ & $0.87^{b}$ & $0.43^{\mathrm{a}}$ & $0.55^{\mathrm{b}}$ & $0.73^{b}$ & $0.75^{b}$ \\
\hline Brain weights & 24 & $0.53^{b}$ & $-0.39^{a}$ & $-0.49^{b}$ & $-0.51^{b}$ & -0.22 & $-0.60^{\mathrm{b}}$ \\
\hline
\end{tabular}

${ }^{\mathrm{a}} \mathrm{P}<0.05,{ }^{\mathrm{b}} \mathrm{P}<0.01$, test of significance of correlation coefficient. 
Table 7 The correlation coefficient gut injury, liver injury, brain injury, MDA, ONOO', VMA, LPS-P, ALP-A and ALP-C in the brain

\begin{tabular}{|c|c|c|c|c|c|c|c|}
\hline & $\mathrm{n}$ & ALP-A & ALP-C & MDA & ONOO & LPS-P & VMA \\
\hline ALP-A & 24 & & 0.30 & -0.25 & $-0.49^{b}$ & $-0.42^{\mathrm{a}}$ & $-0.52^{b}$ \\
\hline ALP-C & 24 & & & 0.57 & $0.51^{b}$ & $0.51^{b}$ & 0.25 \\
\hline MDA & 24 & & & & $0.76^{\mathrm{b}}$ & $0.71^{\mathrm{b}}$ & $0.46^{\mathrm{a}}$ \\
\hline $\mathrm{ONOO}^{-}$ & 24 & & & & & $0.84^{\mathrm{b}}$ & $0.66^{\mathrm{b}}$ \\
\hline LPS-P & 24 & & & & & & $0.63^{b}$ \\
\hline Intestine & 24 & -0.26 & $0.39^{\mathrm{a}}$ & $0.73^{b}$ & $0.80^{\mathrm{b}}$ & $0.61^{b}$ & 0.39 \\
\hline Cecum injury & 24 & -0.36 & $0.38^{\mathrm{a}}$ & $0.50^{b}$ & $0.69^{b}$ & $0.71^{b}$ & $0.66^{\mathrm{b}}$ \\
\hline Fecal loading in the Cecum & 24 & -0.09 & $0.44^{\mathrm{a}}$ & -0.05 & 0.12 & 0.23 & -0.01 \\
\hline Colorectal injury & 24 & -0.09 & 0.20 & -0.05 & 0.12 & 0.23 & -0.01 \\
\hline Liver injury & 24 & -0.17 & $0.53^{\mathrm{b}}$ & $0.76^{\mathrm{b}}$ & $0.65^{b}$ & $0.55^{\mathrm{b}}$ & $0.50^{\mathrm{b}}$ \\
\hline Brain weights & 24 & 0.05 & $-0.63^{b}$ & $-0.39^{\mathrm{a}}$ & $-0.50^{\mathrm{b}}$ & $-0.50^{b}$ & -0.19 \\
\hline
\end{tabular}

${ }^{a} \mathrm{P}<0.05,{ }^{b} \mathrm{P}<0.01$, test of significance of correlation coeficient.

binding rate of serum amylase were significantly higher in HCC + LDSD patients than those with liver and kidney Yin deficiency. HCC + LDSD patients had higher ConA binding rate of serum amylase compared with those with QI and blood stasis. A positive correlation

Table 8 The correlation coefficient between MDA, ONOO', VMA, LPS-P, and ALP-C in the gut, liver and brain

\begin{tabular}{|c|c|c|c|c|c|c|}
\hline $\mathbf{n}$ & $\begin{array}{l}\text { Liver } \\
\text { MDA } \\
\end{array}$ & $\begin{array}{l}\text { Liver } \\
\text { ONOO }\end{array}$ & $\begin{array}{l}\text { Liver } \\
\text { VMA }\end{array}$ & $\begin{array}{l}\text { Liver } \\
\text { LSP-P }\end{array}$ & $\begin{array}{l}\text { Liver } \\
\text { ALP-A }\end{array}$ & $\begin{array}{l}\text { Liver } \\
\text { ALP-C }\end{array}$ \\
\hline \multicolumn{7}{|l|}{ Liver } \\
\hline 24 & & $0.51^{b}$ & $0.60^{b}$ & $0.44^{\mathrm{a}}$ & $0.42^{\mathrm{a}}$ & $0.40^{\mathrm{a}}$ \\
\hline 24 & & & $0.80^{b}$ & $0.63^{\mathrm{b}}$ & $-0.63^{b}$ & $0.60^{b}$ \\
\hline 24 & & & & $0.71^{b}$ & $-0.83^{b}$ & $0.65^{b}$ \\
\hline 24 & & & & & $-0.75^{b}$ & $0.74^{b}$ \\
\hline 24 & & & & & & $-0.86^{b}$ \\
\hline 24 & & & & & & \\
\hline \multicolumn{7}{|l|}{ Gut } \\
\hline 24 & $0.62^{b}$ & $0.84^{b}$ & $0.86^{\mathrm{b}}$ & $0.84^{b}$ & $-0.73^{b}$ & $0.69^{b}$ \\
\hline 24 & $0.55^{b}$ & $0.81^{b}$ & $0.90^{\mathrm{b}}$ & $0.84^{b}$ & $-0.80^{b}$ & $0.68^{b}$ \\
\hline 24 & $0.60^{b}$ & $0.86^{\mathrm{b}}$ & $0.93^{b}$ & $0.76^{\mathrm{b}}$ & $-0.73^{b}$ & $0.60^{b}$ \\
\hline 24 & $0.41^{a}$ & $0.74^{\mathrm{b}}$ & $0.69^{b}$ & $0.59^{b}$ & $-0.64^{b}$ & $0.67^{b}$ \\
\hline 24 & $-0.56^{b}$ & $-0.72^{b}$ & $-0.76^{b}$ & $-0.71^{b}$ & $0.82^{b}$ & $-0.89^{b}$ \\
\hline 24 & 0.29 & $0.63^{b}$ & $0.64^{b}$ & $0.56^{b}$ & $-0.76^{b}$ & $0.66^{\mathrm{b}}$ \\
\hline \multicolumn{7}{|l|}{ Brain } \\
\hline 24 & $0.55^{b}$ & $0.66^{b}$ & $0.80^{b}$ & $0.74^{b}$ & $-0.83^{b}$ & $0.69^{b}$ \\
\hline 24 & $0.61^{b}$ & $0.84^{b}$ & $0.95^{\mathrm{b}}$ & $0.73^{b}$ & $-0.74^{b}$ & $0.62^{b}$ \\
\hline 24 & 0.20 & $0.60^{b}$ & $0.67^{b}$ & $0.54^{b}$ & $-0.53^{b}$ & 0.43 \\
\hline 24 & $0.52^{b}$ & $0.89^{b}$ & $0.85^{b}$ & $0.64^{b}$ & $-0.71^{b}$ & $0.58^{\mathrm{b}}$ \\
\hline 24 & -0.29 & $-0.47^{\mathrm{a}}$ & -0.34 & $-0.53^{b}$ & 0.21 & $-0.41^{\mathrm{a}}$ \\
\hline 24 & $0.35^{\mathrm{a}}$ & $0.36^{a}$ & $0.68^{\mathrm{b}}$ & $0.35^{a}$ & $-0.62^{b}$ & 0.28 \\
\hline
\end{tabular}

${ }^{\mathrm{a}} \mathrm{P}<0.05,{ }^{\mathrm{b}} \mathrm{P}<0.01$, test of significance of correlation coeficient. was found between PSA, LCA, and PNA binding rate of serum amylase and MDA.

\section{Conclusions}

Above all these observations suggest that there was a significant increase in gut-liver-brain injury of $\mathrm{CCI}_{4}+$ ethanol-induced mouse $\mathrm{HCC}$, it is associated with the vicious circle between the oxidative stress, nitrosative stress and $\mathrm{N}$-glycan deficiency and inactivation of ALP in gut, liver and brain through LPS-CA interactions.

LDSD significantly increased gut-liver-brain injury in $\mathrm{CCI}_{4}$ + ethanol-induced mouse $\mathrm{HCC}$, it's maily because LDSD can significantly aggravate the vicious circle between the oxidative stress, nitrosative stress and $\mathrm{N}$ glycan deficiency and inactivation of ALP in gut, liver and brain through LPS-CA interactions.

$\mathrm{XCHD}$ significantly decreased gut-liver-brain injury in $\mathrm{CCI}_{4}$ + ethanol-induced mouse $\mathrm{HCC}$, it's maily because $\mathrm{XCHD}$ can significantly attenuate the vicious circle between the oxidative stress, nitrosative stress and $\mathrm{N}$ - glycan deficiency and inactivation of ALP in gut, liver and brain through LPS-CA interactions, by increased $\mathrm{N}$ glycan and activation of ALP, decreased LPS toxicity, oxidative stress, nitrosative stress, CA (VMA), ultimately to improved the gut, liver and brain injury and the dysfunction of gut-liver-brain interactions.

\section{Abbreviations}

XCHD: Xiaochaihu decoction, which is a classic and famous prescription founded by Zhang Zhong-jing, which is a main prescription treating Shaoyang Syndrome in Shanghanlun; LDSD: Liver depression and spleen deficiency, Main symptoms for the pattern of LDSD are mental depression, sentiment, fatigue, reddish or pale tongue, reduced food intake, fine or fine stringlike pulse; ALP: Alkaline phosphatase; ALP-A: Alkaline phosphatase activity; ALPC: Concanavalin A (ConA)-binding ratios of alkaline Phosphatase; LPS: Lipopolysaccharide; LPS-P: Lipopolysaccharide-phosphate; VMA: 4-hydroxy3-methoxymandelic acid, the end product of both epinephrine and norepinephrine catabolism, was used as an index of catecholamine activity; $\mathrm{ONOO}^{-}$: Peroxynitrite, is a reactive oxygen species that reacts quickly with nitric 
oxide; MDA: Malondialdehyde, is a reactive oxygen species, could reflect oxidative damage to lipids.

\section{Competing interests}

We declare that we have no competing interests.

\section{Authors' contributions}

X-QL conceived of the study, carried out the molecular studies, performed the statistical analysis and drafted the manuscript. X-JH carried out the animal experiments, participated in the molecular studies and helped to draft the manuscript, $\mathrm{H}-\mathrm{XX}$ and $\mathrm{X}-\mathrm{YZ}$ carried out to evaluate the chemical constituents of Xiaochaihu Decoction (XCHD). All authors read and approved the final manuscript.

\section{Authors' information}

Xiaoqiu Liu, Xiaojian Hu, Hong-Xing Xu, Xiao-Ying Zeng. The vicious circle between the oxidative stress and the ALP inactivation through LPScatecholamines interactions.

\section{Acknowledgments}

The authors would like to thank the Laboratory Animal Research Center of Guangzhou University of Traditional Chinese Medicine for providing mouse and plastic mouse cages.

\section{Funding}

This study was supported by the Funds of Guangzhou University of TCM, No.10CX081.

This study was also supported by the Funds of Chinese Internal Medicine (key subject with TCM characters) of Guangzhou University of TCM.

\section{Author details}

${ }^{1}$ Piwei Research Institutes, Guangzhou University of Chinese Medicine, Guangzhou 510405, Guangdong, China. ${ }^{2}$ The Fourth People's Hospital, Zhanjiang 524008, Guangdong, China.

Received: 9 April 2013 Accepted: 13 November 2013

Published: 28 December 2013

\section{References}

1. Oka H, Yamamoto S, Kuroki T, Harihara S, Marumo T, Kim SR, Monna T, Kobayashi K, Tango T: Prospective study of chemoprevention of hepatocellular carcinoma with Sho-saiko-to (TJ-9). Cancer 1995, 76(5):743-9.

2. Shiota G, Maeta Y, Mukoyama T, Yanagidani A, Udagawa A, Oyama K, Yashima K, Kishimoto Y, Nakai Y, Miura T, Ito H, Murawaki Y, Kawasaki H: Effects of Sho-Saiko-to on hepatocarcinogenesis and 8-hydroxy-2'-deoxyguanosine formation. Hepatology 2002, 35(5):1125-33.

3. Ota A, Kaneko YS, Mori K, Nakashima A, Nagatsu I, Nagatsu T: Effect of peripherally administered lipopolysaccharide (LPS) on GTP cyclohydrolase I, tetrahydrobiopterin and norepinephrine in the locus coeruleus in mice. Stress 2007, 10(2):131-6.

4. Lyte M, Vulchanova L, Brown DR: Stress at the intestinal surface: catecholamines and mucosa-bacteria interactions. Cell Tissue Res 2011 343(1):23-32.

5. von Montfort C, Beier JI, Guo L, Kaiser JP, Arteel GE: Contribution of the sympathetic hormone epinephrine to the sensitizing effect of ethanol on LPS-induced liver damage in mice. Am J Physiol Gastrointest Liver Physiol 2008, 294(5):G1227-34.

6. Yuan A, Li Z, Li X, Yi S, Wang S, Cai Y, Cao H: The mitogenic effectors of isoproterenol in human hepatocellular carcinoma cells. Oncol Rep 2010, 23:151-7.

7. Yu LX, Yan HX, Liu Q, Yang W, Wu HP, Dong W, Tang L, Lin Y, He YQ, Zou SS, Wang C, Zhang HL, Cao GW, Wu MC, Wang HY: Endotoxin accumulation prevents carcinogen-induced apoptosis and promotes liver tumorigenesis in rodents. Hepatology 2010, 52:1322-33.

8. Liu X, Liang J, Li G: Lipopolysaccharide promotes adhesion and invasion of hepatoma cell lines HepG2 and HepG2.2.15. Mol Biol Rep 2010, 37:2235-2239.

9. Naor R, Domankevich V, Shemer S, Sominsky L, Rosenne E, Levi B, Ben-Eliyahu S: Metastatic-promoting effects of LPS: sexual dimorphism and mediation by catecholamines and prostaglandins. Brain Behav Immun 2009, 23:611-21.
10. Xu XB, Leng XS, Yang $X$, He ZP: Obstruction of TGF-beta1 signal transduction can decrease the process of hepatocellular carcinoma in mice induced by $\mathrm{CCl}_{4}$ /ethanol. Zhonghua Yi Xue Za Zhi 2004, 84(13):1122-1125.

11. Shimaoka A, Seo S, Minato H: Saponins isolated from Bupleurum falcatum L. components of saikosaponin b. J Chem Soc Perkin 1 1975, 20:2043-2048.

12. Kubota $\mathrm{T}$, Hinoh $\mathrm{H}$ : The constitution of saponins isolated from bupleurum falcatum L. Tetrahedron Lett 1968, 9(3):303-306.

13. Nicole Kristine B: Glucagon-like peptide 2 and inflammatory bowel disease. Calgary: University of Calgary, Department of Medical Sciences, National Library of Canada Press; 2000.

14. Liu XQ, Zhu HL, Ye XW, Tang HQ: The aberrant sugar chains of amylase and different TCM syndrome patterns in primary hepatic cancer as well as the related mechanism. Zhong Liu 2008, 28:322-325.

15. Behr W, Barnert J: Quantification of bone alkaline phosphatase in serum by precipitation with wheat-germ lectin: a simplified method and its clinical plausibility. Clin Chem 1986, 32:1960-1966.

16. Somogyi M: A method for the preparation of blood filtrates for the determination of sugar. J Biol Chem 1930, 86:655-663.

17. Uppu RM, Pryor WA: Synthesis of peroxynitrite in a two-phase system using isoamyl nitrite and hydrogen peroxide. Anal Biochem 1996, 236:242-249.

18. Mihara M, Uchiyama M: Determination of malonaldehyde precursor in tissues by thiobarbituric acid test. Anal Biochem 1978, 86:271-278.

19. Rahmati-Bahram A, Magee JT, Jackson SK: Effect of temperature on aminoglycoside binding sites in Stenotrophomonas maltophilia. J Antimicrob Chemother 1997, 39:19-24.

20. Hurlbert RE, Weckesser J, Mayer H, Fromme I: Isolation and characterization of the lipopolysaccharide of Chromatium vinosum. Eur J Biochem 1976, 68:365-71.

21. Gutteridge JM: A partially automated method for the quantitative determination of urinary 4-hydroxy-3-methoxymandelic acid. Clin Chim Acta 1970, 28:311-6.

22. Zhou L, Yang Y, Tian D, Wang Y: Oxidative stress-induced 1, N6ethenodeoxyadenosine adduct formation contributes to hepatocarcinogenesis. Oncol Rep 2013, 29:875-84

23. Tang $\mathrm{CH}$, Wei $W$, Hanes MA, Liu L: Hepatocarcinogenesis driven by GSNOR deficiency is prevented by iNOS inhibition. Cancer Res 2013, 73(9):2897-904.

24. Xiang Q, Liu Z, Wang Y, Xiao H, Wu W, Xiao C, Liu X: Carnosic acid attenuates lipopolysaccharide-induced liver injury in rats via fortifying cellular antioxidant defense system. Food Chem Toxicol 2013, 53:1-9.

25. Schäper J, Wagner A, Enigk F, Brell B, Mousa SA, Habazettl H, Schäfer M: Regional sympathetic blockade attenuates activation of intestinal macrophages and reduces gut barrier failure. Anesthesiology 2013, 118:134-42.

26. Adham KG, Al-Humaidhi EM, Daghestani MH, Aleisa NA, Farhood MH: Protective role of indomethacin on lipopolysaccharide-stimulated fever induction and cerebral catecholamine biosynthesis in Wistar rat. Neuro Endocrinol Lett 2012, 33:713-21

27. Bentala H, Verweij WR, Huizinga-Van Der Vlag A, Van Loenen-Weemaes AM, Meijer DK, Poelstra K: Removal of phosphate from lipid A as a strategy to detoxify lipopolysaccharide. Shock 2002, 18:561-566.

28. Barna I, Bertók L, Koenig Jl, Makara GB: Radiodetoxified lipopolysaccharide fails to activate the hypophyseal-pituitary-adrenal axis in the rat. Neuroimmunomodulation 2000, 8:128-31.

29. Campbell EL, MacManus CF, Kominsky DJ, Keely S, Glover LE, Bowers BE, Scully M, Bruyninckx WJ, Colgan SP: Resolvin E1-induced intestinal alkaline phosphatase promotes resolution of inflammation through LPS detoxification. Proc Natl Acad Sci U S A 2010, 107:14298-303.

30. Chen KT, Malo MS, Beasley-Topliffe LK, Poelstra K, Millan JL, Mostafa G, Alam SN, Ramasamy S, Warren HS, Hohmann EL, Hodin RA: A role for intestinal alkaline phosphatase in the maintenance of local gut immunity. Dig Dis Sci 2011, 56:1020-7.

31. Tuin A, Huizinga-Van Der Vlag A, Van Loenen-Weemaes AM, Meijer DK, Poelstra K: On the role and fate of LPS-dephosphorylating activity in the rat liver. Am J Physiol Gastrointest Liver Physiol 2006, 290:G377-385.

32. Kellett KA, Williams J, Vardy ER, Smith AD, Hooper NM: Plasma alkaline phosphatase is elevated in Alzheimer's disease and inversely correlates with cognitive function. Int J Mol Epidemiol Genet 2011, 2:114-21.

33. Halling Linder C, Narisawa S, Millán JL, Magnusson P: Glycosylation differences contribute to distinct catalytic properties among bone alkaline phosphatase isoforms. Bone 2009, 45:987-93. 
34. Chrostek L, Cylwik B: The alteration of proteins glycosylation in liver diseases. Pol Merkur Lekarski 2011, 31:60-4.

35. Cottalasso D, Bellocchio A, Pronzato MA, Domenicotti C, Traverso N, Gianelli MV, Marinari UM, Nanni G: Effect of ethanol administration on the level of dolichol in rat liver microsomes and Golgi apparatus. Alcohol Clin Exp Res 1998, 22:730-7.

36. Yasuda J, Eguchi H, Fujiwara N, Ookawara T, Kojima S, Yamaguchi Y, Nishimura M, Fujimoto J, Suzuki K: Reactive oxygen species modify oligosaccharides of glycoproteins in vivo: a study of a spontaneous acute hepatitis model rat (LEC rat). Biochem Biophys Res Commun 2006, 342:127-34.

doi:10.1186/1472-6882-13-375

Cite this article as: Liu et al:: Xiaochaihu Decoction attenuates the vicious circle between the oxidative stress and the ALP inactivation through LPS-catecholamines interactions in gut, liver and brain during $\mathrm{CCl}_{4}+$ ethanol-induced mouse $\mathrm{HCC}$. BMC Complementary and Alternative Medicine 2013 13:375.

\section{Submit your next manuscript to BioMed Central and take full advantage of:}

- Convenient online submission

- Thorough peer review

- No space constraints or color figure charges

- Immediate publication on acceptance

- Inclusion in PubMed, CAS, Scopus and Google Scholar

- Research which is freely available for redistribution 